\title{
Competência textual à entrada no Ensino Superior*
}

\author{
Textual competence at the beginning of Higher \\ Education
}

\author{
Antónia Estrela \\ Escola Superior de Educação de Lisboa \\ Otília Sousa \\ Escola Superior de Educação de Lisboa
}

Resumo

Este trabalho visa a uma reflexão sobre as competências de escrita dos alunos à chegada ao Ensino Superior. São descritas e analisadas as principais dificuldades manifestadas pelos alunos no que diz respeito ao domínio das técnicas de escrita e à própria correção linguística. Faz-se ainda uma análise dos programas de Língua Portuguesa, para o Ensino Secundário, destacando-se as competências descritas como nucleares, no ensino da escrita. A partir daí, tenta-se explicar a existência de diferentes domínios de escrita, que podem ser explicados pela influência da família, nomeadamente o nível de escolarização dos pais, e pela frequência do ensino pré-escolar.

\section{Palavras-Chave}

Escrita, Competência de escrita, Desvios linguísticos 


\section{Abstract}

This study aims at reflecting on the writing skills of students on their arrival at college. The study describes and analyzes the main difficulties experienced by students with regard to the field of writing techniques and linguistic accuracy. An analysis of the Portuguese Language Program, at Secondary Education is also made, with emphasis on core competencies as outlined in the teaching of writing. We attempt to explain the existence of different levels of writing, which can be justified by the predominant role of the family, namely the parent's education, and by enrollment in kindergarten.

\section{Keywords}

Writing, Writing skills, Linguistic deviation 


\section{Introdução}

$\mathrm{N}$

o trabalho que apresentamos convergem vários estudos realizados no âmbito da disciplina de Técnicas de Expressão Oral e Escrita (TEOE), com o intuito de perceber as dificuldades dos alunos para melhor poder intervir no desenvolvimento da sua competência de expressão escrita. O objetivo que norteia este trabalho é o de refletir sobre as competências de escrita dos alunos à chegada ao Ensino Superior. Analisaremos igualmente os programas de Língua Portuguesa, para o Ensino Secundário, salientando as competências descritas como nucleares, no ensino da escrita. Do sucesso do desenvolvimento dessas competências dependerá, em parte, o êxito que os alunos virão a alcançar no Ensino Superior, não só nas unidades curriculares da área de Língua Portuguesa como também em todas as outras.

Se, por um lado, há unidades curriculares majoritariamente práticas e que parecem lançar o domínio da língua para um plano secundário, há, por outro, aquelas que exigem uma proficiência de nível elevado na língua tanto no modo escrito como no modo oral. A questão do domínio do modo escrito impõe-se com bastante acuidade tendo em conta o público a que nos dirigimos, pois para além de grande parte da avaliação ser escrita, esta depende não só do que se escreve mas também do modo como se escreve. Ademais, os nossos alunos serão professores, o que aumenta a responsabilidade de formação, dado que a escrita será uma das suas áreas de intervenção quando forem profissionais de educação.

Numa primeira fase deste trabalho, descreveremos as linhas orientadores do Programa de Português $-10^{\circ}, 11^{\circ}$ e $12^{\circ}$ anos, para cotejarmos o nível proposto com a competência manifestada pelos alunos à entrada no Ensino Superior.

Posteriormente, daremos conta de um estudo levado a cabo por Sousa $\&$ Estrela (2008, 2009a, 2009b, 2009c), que mostra que ainda são muitas as áreas da língua em que um número considerável de alunos revela pouca consolidação de conhecimentos, nomeadamente em nível macroestrutural (a organização textual, a gestão da progressão e continuidade tópica) e em nível da microestrutura 
(sobretudo a morfossintaxe e a semântica). Neste estudo, listam-se alguns desvios mais comuns, dando-se particular destaque à construção gerundiva.

Tentaremos ainda lançar alguma luz sobre o fato de os alunos apresentarem diferentes domínios da escrita quando todos passam, à partida, pelo mesmo programa. Com base num inquérito, veremos se, quando se fala em sucesso escolar, será a escola a ter um papel determinante ou se este caberá à família.

\section{Programa de Português $-10^{\circ}, 11^{\circ}$ e $12^{\circ}$ anos}

Quando um aluno chega ao Ensino Superior, espera-se que domine uma série de ferramentas linguísticas e comunicativas que lhe permitam expor, quer no nível da oralidade, quer no nível da escrita, um conjunto de ideias devidamente organizadas sobre um determinado tópico. Esta será, no entanto, uma situação ideal que muitas vezes não corresponde à realidade com que se deparam os professores do Ensino Superior.

Mas quando se analisa o programa de português para o Ensino Secundário, verificamos que este é um documento extenso e muito completo. Apresentando um currículo detalhado em termos de aprendizagem de escrita, descreve, nas diferentes seções, finalidades e objetivos, sugere metodologias, conteúdos e competências, e esclarece, ainda, a gestão da aprendizagem, contemplando modos de operacionalização e sequências didáticas. Após a análise do programa e dadas a sua extensão e exaustividade no que concerne à escrita, é natural algum cepticismo diante dos níveis de proficiência revelada pela maioria dos alunos ao atingirem o Ensino Superior. Como sabemos, a competência de escrita não é homogênea e a sua aprendizagem faz-se ao longo de toda a escolaridade (KELLOG, 2008), havendo domínios que é fundamental ensinar depois de 12 anos de escolaridade. Persiste, contudo, um grande desfasamento entre o que é o perfil subjacente ao programa do Ensino Secundário e o perfil apurado à entrada no Ensino Superior.

$\mathrm{Na}$ introdução do programa, afirma-se que o Português, constituindo uma disciplina de formação geral, é comum a todas as áreas de formação nos três anos de duração do ciclo: "visa a aquisição de um corpo de conhecimentos e o desenvolvimento de competências que capacitem os jovens para a reflexão e o uso da língua materna." Esta é, em contexto escolar, simultaneamente, "instrumento" e "objeto de aprendizagem", sendo fundamental neste ciclo "o aprofundamento 
da consciência metalinguística". A aula de língua deve desenvolver a eficácia da comunicação, contribuindo para o sucesso na comunicação/interação. Cabendo à escola "incrementar a capacidade de compreensão e expressão oral e escrita do aluno", deve-se promover a "produção de textos orais e escritos adequados...", cuidando da variedade de textos a produzir.

$\mathrm{Na}$ apresentação do programa, salienta-se a importância do ensino da tipologia de textos previstos, apontando-se para a necessidade de instituir uma "oficina de escrita", "entendida como trabalho laboratorial, constituindo um espaço curricular em que a aprendizagem e a sistematização de conhecimentos sobre a língua e os seus usos se inscrevem como componentes privilegiados" (p. 4).

O documento apresenta ainda finalidades e objetivos, destacando-se a importância da expressão oral e escrita coerente, de acordo com "finalidades e situações comunicativas", da reflexão sobre os modos como se organizam os textos/discursos e o desenvolvimento de "processos linguísticos, cognitivos e metacognitivos necessários à operacionalização" das diferentes competências de compreensão e expressão, nas modalidades oral e escrita.

Na descrição de competências, é contemplada a competência discursiva/ textual e a necessidade de promover o "conhecimento das convençóes que subjazem à produção de textos orais e escritos que cumpram as propriedades da textualidade" (p. 8).

O programa contempla, também, processos de operacionalização das competências, seção que contém indicaçōes muito claras sobre modos de ensinar escrita: "produzir diferentes tipos de texto", "expor ideias, exprimir e defender opiniōes", "discutir e argumentar, utilizar argumentos e contra-argumentos, programar a produção oral e escrita, observando as fases: Planificação, Execução e Avaliação.” (p. 10). Segue-se um conjunto exaustivo de operações/ estratégias a implementar em cada uma das fases enunciadas.

Na seção visão geral dos conteúdos, na expressão escrita são enumerados, para cada um dos três anos, diferentes tipos de texto, as fases do processo, os conteúdos que constituem objeto de reflexão. Numa leitura comparada, verificase um corte entre $\mathrm{o} 10^{\circ}$ ano e os outros anos do ciclo, pois neste a escrita centrase em escritos pessoais, enquanto no $11^{\circ}$ e $12^{\circ}$ anos dominam os textos não pessoais. Observa-se, portanto, uma progressão, complementarmente linear e em espiral, no percurso do desenvolvimento da competência de escrita: partindo de textos localizados em relação ao sujeito, vai-se criando distanciamento com 
vista à produção de textos autônomos em relação quer à esfera do eu, quer aos parâmetros enunciativos, de um modo mais global.

A preocupação de exaustividade leva a que o programa introduza sugestóes metodológicas gerais. O programa enfatiza a diagnose, focalizando a relevância que deve ser dada à orientação e às estratégias de recuperação e de acompanhamento nas primeiras semanas de aulas. Dando voz ao que nos parece ser de bom senso e consensual, aconselha a previsão de "um módulo inicial que equacione os problemas relacionados com as competências nucleares da disciplina, que contribua para a aquisição de um patamar comum mínimo a partir do qual seja possível pôr em prática o programa do Ensino Secundário" (p. 16).

Se o programa é extenso e exaustivo, já os descritores de patamar mínimo para pôr em prática o programa de Ensino Secundário (p. 17), transcritos a seguir, nos parecem pouco exigentes. Senão vejamos:

Expressão escrita:

Dominar técnicas fundamentais de escrita compositiva:

- organizar o texto em períodos e parágrafos, exprimindo apropriadamente os nexos temporais e lógicos;

- escrever com correção ortográfica, morfológica e sintática;

- usar vocabulário apropriado e preciso;

- aplicar corretamente regras básicas de pontuação.

Esclarece-se que, "caso o resultado do diagnóstico se mostre insatisfatório", é necessário "desenvolver estratégias e conceber instrumentos que auxiliem na superação das dificuldades..." (p. 17-18). Acrescenta-se que, ao longo do ano, devem ser desenvolvidas atividades com vista à superação das carências detectadas, seguindo-se um conjunto de recomendações para as diferentes competências nucleares. No que à escrita diz respeito, enuncia-se um conjunto de consideraçôes/ recomendações/sugestōes pedagógicas detalhadas e metodologicamente orientadas, enfatizando a necessidade de reflexão sobre escritos e uma prática intensiva da escrita pedagogicamente intencionalizada. Conclui-se que "a análise das dificuldades dos alunos deverá nortear a promoção de estratégias de superação adequadas ao processo de ensino-aprendizagem" (p. 27).

Poder-se-ia pensar que com orientaçôes claras e com uma componente de operacionalização extensa, à entrada no Ensino Superior os alunos teriam 
aprendido a organizar um texto. Na seção seguinte, veremos que tal nem sempre ocorre.

\section{A eficiência no domínio da escrita à entrada no Ensino Superior}

Conscientes de que cada comunidade tem rituais discursivos com características próprias, desconhecidas dos não iniciados, entendemos por que é que os professores das diferentes áreas do saber se queixam da qualidade da escrita dos alunos, mesmo que, muitas vezes, se limitem a apontar a ortografia como problema. O sentido das queixas dos professores baseia-se no fato de os alunos desrespeitarem (ou desconhecerem) as características do que para eles seria um bom texto, ainda que seja difícil o consenso sobre o que é um bom texto (NAUMAN; STIRLING; BORTHWICK, 2011). O desfasamento entre a escrita dos alunos e as expectativas da comunidade em que estes estão a ingressar tem consequências bastante negativas, pois "[While] linguistic identity and language use are two of any sociocultural group's most defining characteristics, probably in none is it more so than in academic communities, where language mediates and enables all other experience and activity" (PRETO-BAY, 2004, p. 87). Como os alunos estão a encetar um novo ciclo de estudos e estão a iniciarse numa comunidade discursiva com idiossincrasias marcadas, é frequente este desajustamento a que muitos professores dão voz.

Com o intuito de verificar a proficiência no domínio da escrita por parte dos alunos que frequentam o $1^{\circ}$ ano do Ensino Superior, efetuou-se, no âmbito da unidade curricular de TEOE, um teste de diagnóstico, constituído por uma parte de avaliação de conhecimento gramatical, em que eram testados conhecimentos de sintaxe, semântica, morfologia, pontuação, e uma parte cujo objetivo era avaliar a competência textual. Nesta segunda parte, era pedido ao aluno para, a partir de um excerto sobre degradação ambiental, redigir um comentário. $\mathrm{O}$ objectivo principal visava à caracterização da escrita dos alunos para elaborar um programa de trabalho que os ajudasse, por um lado, a conhecerem melhor a sua escrita e, por outro, a tomarem consciência das características dos textos da comunidade a que tinham acedido.

Com base na análise dos testes de diagnóstico (nos anos lectivos de 2007/ 2008 e 2008/2009), concluiu-se que as maiores dificuldades dos alunos assentavam na construção de texto não só ao nível da macroestrutura textual (van 
DIJK, 1980), como ao nível da microestrutura (FAYOL, 1985). No que ao primeiro diz respeito, destacam-se as complicações com a gestão da progressão e continuidade tópicas e a relação e ligação entre parágrafos (SOUSA; ESTRELA, 2008).

Em um nível mais local de gestão da informação, observaram-se também dificuldades na estruturação do parágrafo. Este, nos textos analisados, pode ser extensíssimo, constituído por um único período, no qual coexistem várias ideias sem que se perceba ao certo quantas e sem ficar claro qual a hierarquia ou a relação entre elas. Mas pode ser curto, reduzido a um período com uma ou duas oraçóes. E se, per se, não se colocam problemas perante a existência de parágrafos curtos ou parágrafos longos num texto, um texto que é apenas um somatório de parágrafos curtos ou um texto que é apenas um somatório de parágrafos longos e difíceis de entender, não são, em princípio, bons textos.

Notou-se também que nos textos surgiram erros idênticos aos que os alunos identificaram e corrigiram em frases que lhes foram previamente apresentadas no referido exercício de avaliação do conhecimento gramatical (erros de subcategorização, de pontuação, por exemplo). Esta desarticulação entre a identificação de erros e a posterior reprodução na escrita dos mesmos erros levanta algumas questōes importantes. Se, por um lado, este desfasamento permite equacionar a relação entre conhecimento e competência, pois, se é verdade que os alunos identificam e resolvem em frases, por exemplo, erros de pontuação mais ou menos difíceis, também é verdade que os mesmos alunos em situação de escrita de texto cometem esses erros, não os identificando nem corrigindo quando da revisão do texto. Por outro lado, este fato leva-nos a evocar a chamada "sobrecarga cognitiva" da situação de escrita. O reconhecimento da complexidade inerente à situação de escrita leva a que se imponha o ensino da escrita como processo, a criação de instrumentos e a clarificação de estratégias que possibilitem a facilitação processual da tarefa.

Além das questões equacionadas, essa constatação merece reflexão, tendo em conta o modo como se ensina língua. A explicitação de gramática centrada em frases, ignorando ou menorizando a unidade texto, parece não ajudar quando se trata de mobilizar esses conhecimentos em situação de construção de texto. Advogamos, por isso, que o ensino da gramática se faça integrado nas atividades de leitura e escrita (SOUSA, 2010). Nos momentos de revisão de texto identificam-se e discutem-se os problemas, de modo a criar coletivamente um conjunto de saberes que estejam disponíveis na ocasião da elaboração do texto. 
Depois de uma fase preliminar que consistiu na análise de princípios de textualidade (CHAROLLES, 1978) e na descrição e contabilização dos vários desvios presentes nas produçóes escritas dos alunos, os dez melhores textos foram seleccionados, bem como os dez piores. $\mathrm{Na}$ identificação destes desvios, foram tidas em conta questôes morfossintáticas e semânticas. Alguns dos desvios que mais frequentemente surgiram nos vários textos em análise constituem problemas relacionados com a selecção lexical e subcategorização (ex. Isto origina a que se explore os recursos da terra...); com a colocação e seleção dos clíticos (ex. ... se o ar estiver poluído isso poderá-nos causar problemas); com ortografia e morfologia (ex. Deviam pensar mais em medidas que previligiassem/ ... para mostrar-mos aos nossos filhos uma árvores...).

Apesar de ser rica e proveitosa uma análise cuidadosa dos diversos desvios, apenas faremos a eles uma breve referência. Preferimos centrar-nos nas construçôes gerundivas, dado que, nos textos por nós estudados, é elevado o número de usos incorretos deste tipo de construções. A análise será feita na seção que se segue.

\subsection{Da organização textual}

$\mathrm{Da}$ análise dos textos ressaltam as dificuldades de organização textual. Os textos são repetitivos, apresentando parágrafos mal estruturados ora repetindo sem novidade o anteriormente afirmado, ora introduzindo informação não relacionada com a dada previamente. Estas dificuldades revelam uma gestão deficiente dos princípios da progressão e continuidade tópica (CHAROLLES, 1978). Como sabemos, o texto define-se como um todo uno e coeso (HALLIDAY; HASAN, 1984) em que a informação se organiza de forma articulada e hierarquizada. O texto é entendido, assim, como uma unidade completa do ponto de vista sintático, semântico e também pragmático. Neste contexto, a coesão e a coerência surgem como princípios de níveis distintos que subjazem à organização da informação e que definem textualidade (BEAUGRANDE; DRESSLER, 1981). Enquanto o primeiro diz respeito a marcadores linguísticos, o segundo relaciona-se com a ligação entre a representação de mundo plasmada pelo texto e as representações de mundo do escritor/leitor. Segundo Charolles (1978), são quatro as metarregras da coerência: progressão, continuidade, relação e não contradição. Assim, para que um texto seja coerente, é necessário que de uma frase para a seguinte haja elementos que se repitam, que seja acrescentada 
informação nova, que os elementos representados estejam ligados e que entre eles não haja contradição.

Deste modo, num texto, de parágrafo em parágrafo é necessário gerir a tensão essencial entre a repetição de elementos estruturadores que assegura a coesão textual e a introdução de informação nova que faz o texto avançar. É nesta tensão quase paradoxal entre o conhecido e o novo que se tece a malha textual. Segundo este princípio, é necessário introduzir elementos novos, mas assegurar que o que é novo surja ligado ao já referido, de modo a que o texto se apresente como tessitura. $\mathrm{O}$ excerto a seguir, em que se sublinha a informação nova e se coloca em itálico a informação já conhecida, ilustra a dificuldade dos nossos alunos em gerirem progressão e continuidade tópica:

Uma lixeira a céu aberto polui tanto os solos como a população. Pois uma lixeira ao contaminar os solos afeta tudo a nível desse solo, e é disso que este excerto trata.

Os alimentos produzido nos solos vêm contaminados, ou seja, afetando a saúde dos animais e da população. Uma lixeira a céu aberto não afeta só a geração presente mas também a geração futura, tornando este problema, um problema muito grave.

Como se verifica, o grau de informatividade do segundo parágrafo é muito baixo, pois acrescenta pouca informação nova em relação ao anterior. Compare-se este excerto com o exemplo seguinte retirado do corpus Cetem Público:

É de partir o coração de quem tem o mínimo de sensibilidade ver todos esses cáes e gatos a vaguearem pelas ruas e estradas, de olhos esgazeados, à procura dos donos, uns andando sem parar, até a exaustão, a fome e a sede os atirarem para uma berma, outros acabando atropelados, enquanto os ex-donos se bronzeiam pelas praias e se enfartam com grandes sardinhadas.

Como vemos, a quantidade e qualidade da informação nova (sublinhado) é muito diferente nos dois excertos, sendo, neste segundo excerto, a informação nova muito superior à informação já conhecida, recorrendo o jornalista a estratégias diferenciadas para assegurar a coesão textual: retomadas anafóricas, relações lexicais. Além das retomadas anafóricas uns, outros, ex-donos, bermas indicadas a itálico, há, como já foi referido, um outro mecanismo de coesão que 
utiliza as propriedades semânticas do léxico para criar um texto coeso, sem recorrer a anáforas: vejam-se as relações entre ruas e estradas e bermas e atropelados. Faz parte do nosso conhecimento do mundo que as bermas são partes de estrada, enquanto atropelados está ligado ao universo de referência evocado por ruas e estradas. De igual modo se organizam as relações entre vaguear, olhos esgazeados e acabando atropelados. Os exemplos ilustram as relaçôes que se podem estabelecer entre palavras: retomando o mesmo referente (relação anafórica), no primeiro caso, ou estabelecendo associações semânticas, aproximando-se das noções de campo lexical ou de conhecimento enciclopédico (HALLIDAY; HASAN, 1984), nos outros exemplos.

Se há dificuldades na gestão da informação globalmente, que, como se pode observar, ora leva à repetição, redundando em textos pouco informativos, ora leva à não relação entre assuntos, produzindo rupturas temáticas, verifica-se também que a competência para a estruturação de parágrafo não está estabilizada. A falta de consciência de parágrafo como unidade de informação é revelada a dois níveis: na organização interna do parágrafo e na articulação entre parágrafos.

Na unidade complexa que é o texto, podemos definir outras unidades: a menor unidade de informação seria a oração, unidades intermédias seriam o período e o parágrafo e uma unidade maior seria a sequência (no sentido de ADAM, 1992).

As sequências podem delimitar-se atendendo a critérios (i) pragmáticos, alteração da função comunicativa (narrar, descrever, expor, argumentar...); (ii) semânticos, alteração de tema ou de macroestrutura textual (passagem de desenvolvimento à conclusão na argumentação); (iii) estruturais, mudança de interlocutores, por exemplo no diálogo. A noção de sequência é importante porque, ainda que por vezes seja difícil delimitá-la, permite perceber a heterogeneidade inerente ao próprio texto: não há textos apenas descritivos ou narrativos ou explicativos (há sempre combinação de sequências, por exemplo, no texto narrativo alternam sequências narrativas, com sequências descritivas e dialogais).

O parágrafo constitui uma unidade de informação que integra as sequências. A conceituação do parágrafo não é simples e pode ser objeto de ensino durante toda a escolaridade. Por exemplo, ao terminar o $1^{\circ}$ ciclo, os alunos revelam ainda dificuldades na escrita de parágrafos narrativos (SOUSA; SILVA, 2003). Além da conceituação do parágrafo como unidade de informação, em que 
de algum modo o espaço em branco dá tempo ou indicação ao leitor para sintetizar o que acabou de ler antes de iniciar novo parágrafo, há necessidade de refletir sobre o objetivo do parágrafo: pretende-se descrever? ou explicar? são introduzidas ideias novas ou ilustra-se e apoia-se o já introduzido?

Além do mais, no ensino aprendizagem do comentário, é necessário explicitar a estrutura do parágrafo descritivo, do parágrafo informativo e do parágrafo argumentativo. A primeira definição de parágrafo (uma asserção seguida de ilustraçôes) tem de evoluir rapidamente, para que o aluno ultrapasse uma escrita ingênua, abundante, repetitiva. O ensino explícito da estruturação do parágrafo ajuda os alunos a ganhar consciência das dificuldades que experimentam e a adquirir ferramentas para organizarem as suas ideias. Os problemas revelados perante a estruturação do parágrafo e do período traduzemse, entre outros, na utilização de construções gerundivas.

\section{A construção gerundiva: um desvio}

O parágrafo é, como vimos, constituído por períodos e estes por orações que devem clarificar as relaçóes que se estabelecem dentro do período e entre períodos. Uma das conclusóes decorrentes da nossa análise foi a dificuldade manifestada pelos alunos no uso das orações gerundivas (SOUSA; ESTRELA, 2009b). Ainda que as referidas dificuldades se situem ao nível da organização do período e do parágrafo, parecem-nos de algum modo decorrer de um problema mais vasto: o da organização da informação.

Como referimos, dos problemas observados, pelo elevado número de ocorrências numa quantidade elevada de produções, escolhemos tratar os desvios relacionados com as orações gerundivas. ${ }^{1}$ Relativamente aos textos analisados, fez-se um levantamento de todas as ocorrências de gerúndio, quer quando ocorria devidamente, quer quando tal não acontecia. O que se nota é que nas três turmas $^{2}$ houve usos incorretos do gerúndio, mas apenas na turma 1, a quantidade de usos incorretos ultrapassou a dos usos corretos: 


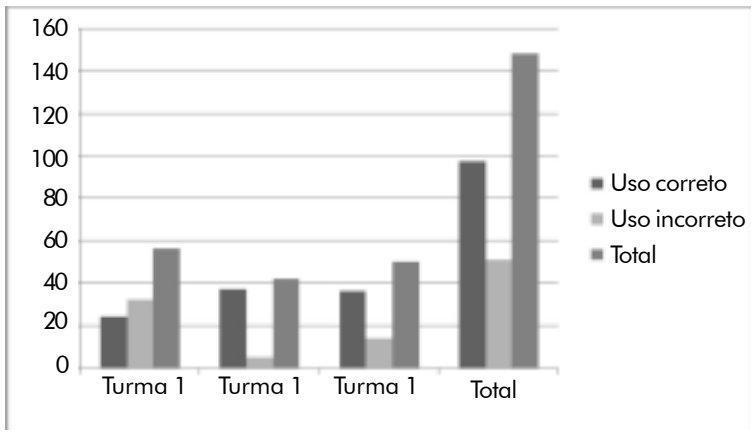

GRÁFICO 1 - Total de ocorrências de gerúndios nas três turmas

Parece-nos relevante que, num total de 148 ocorrências de construções com gerúndio, 51 tenham sido incorretas. Curiosamente, a turma em que ocorrem mais erros é a turma em que um maior número de alunos faz uso do gerúndio. A hipótese que colocamos é a de que os alunos terão consciência das suas dificuldades na utilização desta construção e optam por não a utilizar. Esta poderá ser, portanto, a estratégia para evitar o erro.

Seguidamente, apresentamos alguns excertos em que é feito um uso desviante do gerúndio. Atente-se, por exemplo, na estrutura de enumeração que pressupóe a existência de elementos que sejam semelhantes.

(1) As lixeiras a céu aberto, as descargas de lixo nos mares, nos rios são gravíssimas, fazendo com que haja uma contaminação da água, água essa que é essencial à vida, mas fazendo também com que ecossistemas com animais e plantas se deteriorem, acabando por vezes por chegar à extinção de espécies.

Penso que os governos do mundo se deveriam unir, tentando diminuir a poluição global, contribuindo para um planeta mais limpo, mais cuidado, para uma melhor qualidade de vida, mas também para uma melhor saúde pública, preservando ecossistemas e espécies tão importantes no nosso planeta. [Turma 1, Texto 8]

Nesse excerto, está presente uma asserção que inicia os parágrafos, mas depois acrescenta-se informação na frase sem se ter em conta a relação entre as partes. Neste sentido, a organização é feita tendo por base o princípio da linearidade, sendo o princípio da hierarquia posto de parte, o que revela uma competência textual incipiente e falta de consciência do processo de escrita. 
A atribuição de um sujeito ao gerúndio é também problemática para os nossos alunos. Vejamos os exemplos (2) e (3):

(2) Do mesmo modo, esses gases libertam-se também subterraneamente, fazendo com que os solos percam a sua qualidade e deixem de ser favoráveis à produção de alimentos, comprometendo as geraçóes atual e futura. [Turma 2, Texto 6]

(3) Um excerto desse mesmo artigo referia-se aos perigos que essas mesmas lixeiras representam, tanto para a vida humana, como para a fauna e a flora, comprometendo assim o futuro da vida na terra. [Turma 3, Texto 5]

No exemplo (2), não fica claro se fazendo e comprometendo partilham o mesmo sujeito. Seria mais adequado que o segundo verbo (comprometendo) ocorresse noutro tipo de construção alternativa.

Outro desvio associado não só a orações gerundivas, mas também a outro tipo de orações, assenta na ocorrência da subordinada sem a respectiva subordinante:

(4) Recusando até a integrar na Cimeira da Terra, que ocorreu no Brasil. [Turma 3, Texto 1]

(5) Condicionando as gerações seguintes, se o problema não for resolvido. [Turma 3, Texto 4]

Os alunos recorrem ainda ao gerúndio quando pretendem dar conta de enumeraçôes, esquecendo-se, por um lado, que a língua dispõe de outras estratégias para alcançar tal objetivo e, por outro, que o uso de orações gerundivas impõe algumas restrições, nomeadamente de coocorrência:

(6) Conscientização essa que deveria consistir em enraizar os verdadeiros valores, não só em ensinar a proteger àqueles que nos rodeiam, conservando assim este bem comum a todos.

É por isso que é preciso acabar com estas lixeiras a céu aberto, tratando do lixo de modo que venha a ser reutilizado para trazer benefícios ao meio ambiente, colocando em prática o processo de reciclagem, canalizando os esgotos enfatizando assim não só o conhecer como o praticar.

Relembrando a distinção feita por Lobo $(2002)^{3}$ entre gerundivas de frase e gerundivas de predicado, notamos um maior uso das segundas por parte dos nossos alunos. As gerundivas de predicado são apresentadas como mais dependentes do predicado matriz, exibindo, como tal, mais restrições internas. Este fator poderá ser uma explicação para os erros encontrados. 
Poderemos também colocar a hipótese de estes erros decorrerem da ausência de planificação do texto e da falta de reflexão sobre a unidade parágrafo, nomeadamente da não identificação de relações hierárquicas entre os seus diferentes elementos. Tal leva a estratégias de textualização condicionadas pela linearidade discursiva e próximas da simples justaposição de informação, sem ter em conta relaçôes de coocorrência e interdependência. Estando identificada esta dificuldade, é necessário fazer um ensino explícito do uso da construção gerundiva. Este é apenas um pequeno passo no sentido de tentar colmatar as diversas falhas que os alunos ainda apresentam ao entrar no Ensino Superior.

\section{Diferentes domínios da escrita: uma questão socioeconômica?}

De um modo relativamente evidente, é fácil verificar que alguns dos alunos que chegam ao Ensino Superior estão longe de dominar a variedade de língua que lhes permite ter sucesso na comunidade que acabam de integrar. Neste sentido, impõe-se a pergunta: por que motivo os alunos apresentam diferentes competências na escrita se passam todos pelo mesmo programa. O certo é que não só os professores das unidades curriculares da área de Língua Portuguesa, como também muitos outros, se queixam das dificuldades na transposição para o papel dos conteúdos supostamente apreendidos pelos alunos. Para estes, a escrita raras vezes pressupõe uma construção de conhecimentos quer do processo de escrita propriamente dito, quer do funcionamento de determinados tipos textuais, o que depois impede a criação de textos de excelência.

Ao ingressarem no Ensino Superior, os alunos integram uma comunidade com práticas de escrita diferenciadas. Se, por um lado, os chamados textos acadêmicos apresentam formatos variados, por outro, têm características transversais: são textos objetivos, com léxico muito específico, universos de referência próprios das diferentes áreas do saber, e com uma complexidade sintática de nível elevado. Assim, em relação ao Ensino Secundário, os alunos precisam de aprender a escrever num registo diferente: com léxico particular, estruturas sintáticas complexas e operaçōes de textualização próprias de textos com um grande grau de autonomia em relação ao universo pessoal. Torna-se assim necessário socializar os alunos numa comunidade diferente das anteriores com estratégias de comunicação diferenciadas e textos específicos. Por isso é tão 
importante uma propedêutica à escrita acadêmica. Como refere Larsen-Freeman (2003, p. 47), "We do not communicate through reference to prior, fixed abstract forms but rather we create language as we go, both individually and as communities".

Em certo sentido, no Ensino Superior, considerou-se, durante muito tempo, que a responsabilidade do domínio da língua escrita pertencia exclusivamente ao estudante. Estava de certo modo subjacente que os alunos estariam devidamente equipados com estratégias e competências para um bom domínio da sua língua. No entanto, constata-se que esta era a situação ideal, mas não a real, tendo em conta, entre outros fatores, o alargamento dos perfis socioeconômicos dos alunos (CHALL; JACOBS, 1996; HALLIDAY, 1996). As instituições, dado o perfil de competências de escrita revelado pelos alunos à entrada no Ensino Superior, deram-se conta de que é necessário continuar o ensino de estratégias de escrita que permitam aos sujeitos a melhoria da sua performance. Mais do que minimizar dificuldades, o que está em causa é o desenvolvimento de competências. Um exemplo é a criação da unidade curricular de Técnicas de Expressão Oral e Escrita, na Escola Superior de Educação de Lisboa, com a qual se pretende que os alunos desenvolvam competências gerais da escrita, da oralidade e ainda competências metalinguísticas, metacomunicativas e metatextuais, para além de competências de estudo que lhes permitam aceder aos textos observando as estruturas ao serviço da construção da significação e pensar a escrita como texto com um fim específico e um leitor em mente (KELLOG, 2008). Esta aproximação aos textos, tendo em conta a estrutura e os mecanismos sintático-semânticos característicos aos textos de determinada área de saber, é fundamental na aprendizagem do discurso acadêmico, pois, como Hasan (1996), acreditamos que as possibilidades de sucesso dos alunos "(...) will be considerable enhanced if they are enabled to produce the sorts of discourse which are valuated within the educational context".

De modo a perceber quais as variáveis que explicam a discrepância de competências entre alunos que escrevem bem e alunos que escrevem mal, efetuou-se um inquérito que visava, por um lado, caracterizar as concepções dos nosso alunos sobre escrita e, por outro, relacionar as representaçóes sobre a escrita, o meio familiar e o percurso escolar (SOUSA; ESTRELA, 2009c). O inquérito foi realizado com a participação de quarenta alunos dos cerca de trezentos que frequentaram a Unidade Curricular de TEOE nos anos escolares 
2007/2008 e 2008/2009. Escolheram-se os vinte alunos considerados mais competentes em escrita e os vinte alunos considerados menos proficientes.

As principais conclusões deste inquérito apontam para a importância das habilitaçôes dos pais na competência de escrita dos estudantes. Os alunos que escrevem melhor são aqueles cujos pais tiveram uma escolarização mais longa: $58 \%$ têm o $12^{\circ}$ ano ou mais; $38 \%$ têm mais de 15 anos de escolaridade. Relativamente aos alunos que escrevem pior, $54 \%$ dos pais têm até 6 anos de escolaridade, tendo $33 \%$ até 4 anos de escolarização.

Verificou-se também que, no que diz respeito às representações sobre o percurso escolar e a aprendizagem da escrita, não há diferenças entre os dois grupos: alunos proficientes em termos de escrita e alunos que escrevem com dificuldade. No grupo de alunos que escrevem melhor, ressalta o fato de terem todos frequentado o ensino pré-escolar, enquanto no outro grupo isso não se verifica. Terá o ensino pré-escolar um impacto tão grande em termos de aprendizagem ou será que este é mais um indicador da preocupação das famílias com a escolarização e aprendizagens dos seus filhos? Segundo um relatório do PISA, PISA in focus 2011, os alunos de 15 anos que frequentaram o ensino préprimário mais do que um ano apresentam melhores resultados do que os que não frequentaram. $\mathrm{O}$ mesmo relatório indica também que os alunos de estratos socioeconômicos mais elevados frequentam mais o ensino pré-primário.

Interessante, também, é o fato de só metade dos alunos que escrevem mal reconhecer que tem dificuldades de escrita. Verificando-se nos dois grupos dificuldades na organização textual, os alunos que escrevem mal assinalam que têm apenas dificuldades na ortografia, enquanto os alunos mais proficientes referem ter limitações na organização do texto. As diferenças na representação dos professores e alunos sobre boa escrita é também assinalada por Addison \& McGee (2010, p. 161-162). Num inquérito em que perguntam a alunos e professores sobre a competência de escrita dos primeiros, estes reclamam ter uma competência de escrita muito superior à apontada pelos professores.

Com base no inquérito, conclui-se também que os alunos menos proficientes provêm de famílias cujos progenitores têm menos escolarização e cujos hábitos de escrita estão mais ligados a uma escrita funcional ligada a tarefas do dia a dia (por exemplo, listas de compras, cheques) e menos compositiva. Assinale-se igualmente uma discrepância entre o que referem os alunos e a representação dos professores: embora a maioria dos alunos assinale que planifica e revê os seus 
textos, estes são comportamentos que não observamos nas aulas. Os alunos tendem a começar a escrever quando se lhes dá o tema e quando acabam de escrever entregam o texto, o que nos leva a questionar até que ponto concebem o texto como produto final de um processo recursivo, como mencionado no programa do Secundário.

Como assinalamos, da leitura do programa do Ensino Secundário, conclui-se que o ensino da escrita é muito valorizado. Além disso, o programa preconiza o ensino do processo, partindo da observação das competências dos alunos. O que verificamos, no entanto, é que os alunos estão longe do perfil para que aponta o programa. A interrogação principal é por que é que se verifica essa discrepância? Por que é que os alunos não planificam os textos e a revisão se resume a níveis superficiais? Por que é que para a maioria dos alunos a concepção de parágrafo é tão incipiente?

Por que é que na escrita, à semelhança do que acontece na leitura para alunos de 15 anos segundo o PISA, a escolarização dos pais é tão importante? Se o ensino é feito em sala de aula, o que acontece durante as aulas? Ou será que o lugar da escrita é em casa (GRAÇA, 2009) e os pais com menos escolarização não conseguem ajudar nos trabalhos de casa?

A concepção do que a escrita é um "dom" e, por isso, não é objecto de ensino observa-se em muitas salas de aula. Frequentemente na sala de aula leemse e interpretam-se textos e, no final da aula, como trabalho de casa, pede-se um texto (GRAÇA, 2009), normalmente, uma resposta pessoal, criativa, ao texto lido. Este entendimento da escrita e do ensino da escrita está presente em demasiadas salas de aula em Portugal, em clara oposição ao programa vigente.

\section{Discussão}

Depois desta reflexão, parece-nos cada vez mais importante ter em conta os processos de operacionalização das competências tal como surgem descritas no programa do Ensino Secundário, no sentido em que tem de ser feito um ensino refletido, reflexivo e contínuo em torno da prática da escrita. A escrita, como processo, tem de ocupar um lugar de relevo no contexto de sala de aula e, numa situação ideal, no dia a dia dos alunos, quer na escola, quer em casa, sendo a escola um lugar de convergência de escrita. Neste caso, trata-se da escrita como negociação de sentidos e aproximação dos mecanismos linguísticos próprios do discurso da escola. A reflexão acerca da escrita e dos registros escritos 
deve ser orientada para o contexto discursivo e para os contextos sociais em que ganha forma (HASAN, 1996).

$\mathrm{O}$ ensino superior deve dar continuidade às aprendizagens, sobretudo numa perspectiva de ensino explícito de diferentes gêneros e tipos de texto para diferentes públicos e com diversas finalidades, pois, se a escrita se destina à reconstrução da significação pelo leitor, este deve começar a ser central, para quem escreve, quer na escrita de textos acadêmicos, quer na escrita de textos de outros registros.

\section{Notas}

*Todo este trabalho assenta em dados referentes ao português de Portugal.

${ }^{1}$ Este tema é mais detalhadamente tratado em Sousa \& Estrela (2009).

${ }^{2} \mathrm{Na}$ realização deste trabalho, foram seleccionadas aleatoriamente 3 das 5 turmas do curso, o que perfaz um total de 81 textos.

${ }^{3}$ Lobo (2002) clarifica a diferença entre as gerundivas de frase e as de predicado, distinguindo-as, primeiramente, quanto aos valores semânticos típicos que lhes estão associados.

Se, por um lado, as gerundivas de frase expressam especialmente valores como a condição, a causa, a concessão e o tempo (não simultâneo), as gerundivas de predicado expressam tipicamente o modo/meio, o tempo (simultâneo), e um valor que se situa entre a condição e o modo.

\section{Referências}

ADAM, J-M. Les textes: types et prototypes. Paris: Nathan, 1992

ADDISON, J.; McGEE, S. J. Writing in high school/writing in college: research trends and future directions. College Composition and Communication. National Council of Teachers of English, v. 62, n.1, p. 147-179, 2010.

BEAUGRANDE, R.; DRESSLER, W. Introduction to Text Linguistics. London: Longman, 1981.

CHALL, J.S.; JACOBS, V. A Study of the Literacy Development of Low-income Children. In: SHIMRON, J. (Ed.). Literacy and Education: Essays in Memory of Dina Feitelson. New Jersey: Hampton Press, 1996. p. 34-46. 
CHAROLLES, M. Enseignement du Récit et Cohérence du Texte. Langue Française, v. 38, p. 7-41, 1978.

COELHO, M. C. (Coord.). Programa de Português. $10^{\circ}, 11^{\circ}$ e $12^{\circ}$ Anos. Lisboa: Ministério da Educação. Direcção Geral de Inovação e de Desenvolvimetno Curricular, 2002.

FAYOL, M. Le Récit et sa Construction. Paris: Nathan, 1985.

GRAÇA, M. M. Contributos para a reflexão sobre a formação de leitores literários em contexto escolar. 2009. Dissertação. (Mestrado em Ciências da Educação) - Instituto de Educação da Universidade de Lisboa, Lisboa, 2009.

HALLIDAY, M. A. K. Literacy and linguistics: a funcional perspective. In: HASAN, R.; WILLIAMS, G. (Ed.). Literacy in Society. Nova Iorque: Longman, 1996. p. 339-376.

HALLIDAY, M.; HASAN, R. Cohésion in English. London: Longman, 1984.

HASAN, R. Literacy, Everyday Talk and Society. In: HASAN, R.; WILLIAMS, G. (Ed.). Literacy in Society. Nova Iorque: Longman, 1996. p. 377-424.

KELLOGG, R. Training Writing Skills: a Cognitive Developmental Perspective. Journal of Writing Research, v. 1, p. 1-26, 2008.

LARSEN-FREEMAN, D. Teaching Language: From Grammar to Grammaring. Boston: Heinle, 2003.

LOBO, M. Aspectos da sintaxe das oraçōes gerundivas adjuntas do português. In XVII Encontro Nacional da Associação Portuguesa de Linguística. Actas... Lisboa: APL, 2002. p. 247-265.

NAUMAN, A. D.; STIRLING, T.; BORTHWICK, A. What makes writing good? An essential question for teachers. The Reading Teacher, v. 64, 5, p. 318-328, 2011.

OCDE. Does participation in pre-primary education translate into better learning outcomes at school? PISA in Focus 1. 2011. Disponível em: <http:// www.pisa.oecd.org/dataoecd/37/0/47034256.pdf>. Acesso em: 26 abr. 2011.

PRETO-BAY, A. M. The socio-cultural dimension of academic literacy development and the explicit teaching of genres as community heuristics. The Reading Matrix, v. 4, n. 3, p. 86-117, 2004.

SOUSA, O.; ESTRELA, A. Écrire à l'université: Jeux et Enjeux Didactiques. Approches comparées de l'enseignement des langues et de la formation des enseignants de langues. Paris: L'Harmattan, 2009a. p. 427-440. 
SOUSA, O.; ESTRELA, A. A construção gerundiva: uma construção problemática? In: PINTO, P. F. (Ed). Gramática para que te Quero?! O Ensino da Gramática: Sentido(s) e Possibilidades. Lisboa: APP, 2009b. p. 222-239.

SOUSA, O.; ESTRELA, A. Literacy background and writing at the post-secondary level. Poster apresentado na VII Conference of the International Association for the Improvement of Mother Tongue Education IAIMTE. Toronto, 2009c.

SOUSA, O.; ESTRELA, A. On textual development: writing at the post-secondary level. Poster apresentado na 11th International Conference of the EARLI (Special Interest Group on Writing). Lund, 2008.

SOUSA, O.; SILVA, M. E. O texto narrativo no $1^{\circ}$ Ciclo: detecção de alguns problemas. In: BÁRRIOS, A.; RIBEIRO, J. (Ed.). II Encontro Nacional de Investigação e Formação. Actas... Lisboa: CIED, p. 181-192, 2003.

SOUSA, O. C. Do trabalho de texto à reflexão linguística. In: SOUSA, O. C.; CARDOSO, A. (Ed.). Desenvolver competências em lingua: percursos didácticos. Lisboa: Cied/Colibri, 2010. p. 111-143.

Van DIJK, T. Text and Context. Explorations in the Semantics and Pragmatics of Discourse. London: Longman, 1980. 